\title{
Anal Verrucous Carcinoma
}

National Cancer Institute

\section{Source}

National Cancer Institute. Anal Verrucous Carcinoma. NCI Thesaurus. Code C7470.

A large, well differentiated squamous cell carcinoma with a cauliflower-like appearance, characterized by the presence of an exophytic and endophytic growth pattern.

Morphologically, there is papillomatosis and acanthosis present, however cytologically the neoplastic squamous cells have a benign appearance. Dysplastic changes are minimal. It does not respond to conservative treatment and it is regarded by many authors as an intermediate lesion between condyloma acuminatum and squamous cell carcinoma. 